\title{
Safety Communication Networks: FEMALES IN SMALL WORK CREWS
}

\section{FINAL PROJECT REPORT}

\author{
by \\ Leigh Allison and Jessica Kaminsky \\ University of Washington \\ Sponsorship: \\ PacTrans \\ for \\ Pacific Northwest Transportation Consortium (PacTrans) \\ USDOT University Transportation Center for Federal Region 10 \\ University of Washington \\ More Hall 112, Box 352700 \\ Seattle, WA 98195-2700
}

In cooperation with US Department of Transportation-Research and Innovative Technology Administration (RITA)

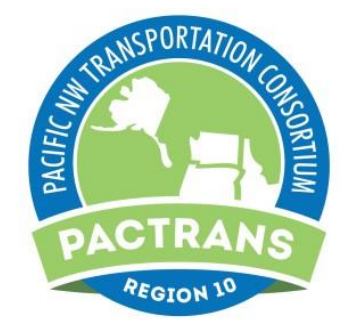




\section{Disclaimer}

The contents of this report reflect the views of the authors, who are responsible for the facts and the accuracy of the information presented herein. This document is disseminated under the sponsorship of the U.S. Department of Transportation's University Transportation Centers Program, in the interest of information exchange. The Pacific Northwest Transportation Consortium, the U.S. Government and matching sponsor assume no liability for the contents or use thereof. 


\section{Technical Report Documentation Page}

\begin{tabular}{|c|c|c|}
\hline 1. Report No. & 2. Government Accession No. & 3. Recipient's Catalog No. \\
\hline \multirow{2}{*}{\multicolumn{2}{|c|}{$\begin{array}{l}\text { 4. Title and Subtitle } \\
\text { Safety Communication Networks: FEMALES IN SMALL WORK CREWS }\end{array}$}} & 5. Report Date: 10/31/2016 \\
\hline & & 6. Performing Organization Code \\
\hline \multicolumn{2}{|c|}{$\begin{array}{l}\text { 7. Author(s) } \\
\text { Leigh Allison and Jessica Kaminsky }\end{array}$} & 8. Performing Organization Report No. \\
\hline \multirow{2}{*}{\multicolumn{2}{|c|}{$\begin{array}{l}\text { 9. Performing Organization Name and Address } \\
\text { PacTrans } \\
\text { Pacific Northwest Transportation Consortium } \\
\text { University Transportation Center for Region } 10 \\
\text { University of Washington More Hall } 112 \text { Seattle, WA 98195-2700 }\end{array}$}} & 10. Work Unit No. (TRAIS) \\
\hline & & $\begin{array}{l}\text { 11. Contract or Grant No. } \\
\text { DTRT13-G-UTC40 }\end{array}$ \\
\hline \multirow{2}{*}{\multicolumn{2}{|c|}{$\begin{array}{l}\text { 12. Sponsoring Organization Name and Address } \\
\text { United States of America } \\
\text { Department of Transportation } \\
\text { Research and Innovative Technology Administration }\end{array}$}} & $\begin{array}{l}\text { 13. Type of Report and Period Covered } \\
\text { Research } 1 / 15 / 2015-12 / 15 / 2016\end{array}$ \\
\hline & & 14. Sponsoring Agency Code \\
\hline
\end{tabular}

16. Abstract:

Construction workers experience one of the highest rates of injuries and fatalities in the U.S. Communication is essential for construction safety. Recent research has shown that worker demographics affect the diffusion of safety knowledge in small field crews. Noting the lack of gender diversity among construction workers, this research studied how gender affects work crew safety communication and safety performance. The objective of this research was to analyze the relationships between worker gender and communication patterns in transportation construction work zones in Washington state by using Social Network Analysis (SNA). We hypothesized that work crews with both male and female members (a decrease in work crew homophily) would show different communication patterns and worse safety performance than crews without gender diversity. The data showed that females have significantly $(\mathrm{p}<0.05)$ lower amounts of in-degree (incoming ties) and in-closeness (distance for information to travel) according to a Mann-Whitney test than the males in the mixed-gender crews. Furthermore, mixed-gender crews had a less than average formal density and higher than average informal density than the all-male crews. Practically speaking, this research showed that mixed-gender work crews have different safety communication patterns than homogenous male crews. Further research is needed to determine whether these differences are widespread, how females affect the patterns, and how these differences affect safety performance.

\section{Key Words}

Safety communication, females, women, transportation construction report)

Unclassified.

Form DOT F 1700.7 (8-72)

20. Security Classification (of this
page)
Unclassified.

Reproduction of completed page authorized

\section{Distribution Statement}

No restrictions.

\begin{tabular}{|l|l|}
\hline 21. No. of Pages & 22. Price \\
& NA \\
\hline
\end{tabular}




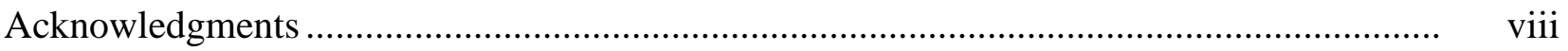

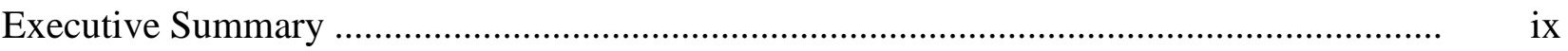

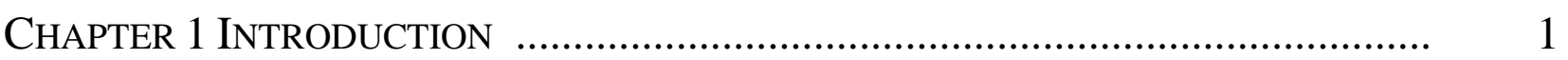

1.1 Problem Statement f............................................................................. 2

1.2 Project Goal .......................................................................................... 2

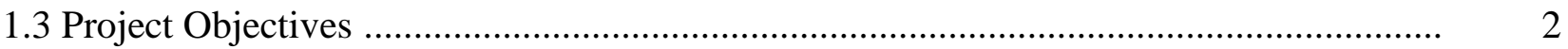

CHaPter 2 Literature ReVIEW ........................................................ 5

2.1 Safety Communication ............................................................................ 5

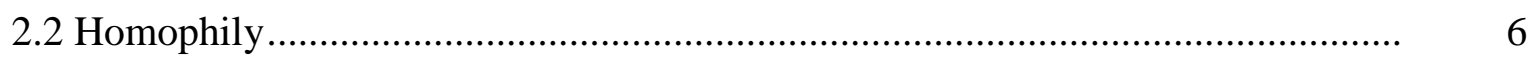

2.3 Females in Construction ........................................................................... 8

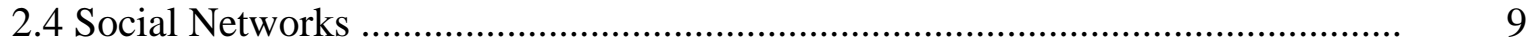

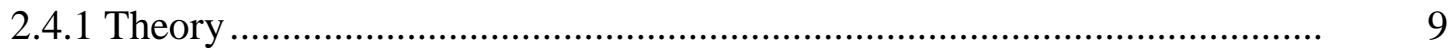

2.4.2 Network Characterization ............................................................. 10

CHAPTER 3 STUDY DATA ................................................................. 13

CHAPTER 4 METHDOLOGY .................................................................. 15

CHAPTER 5 ReSUltS ........................................................................ 19

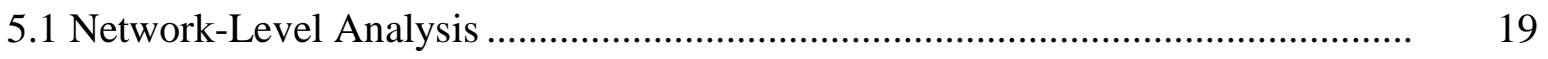

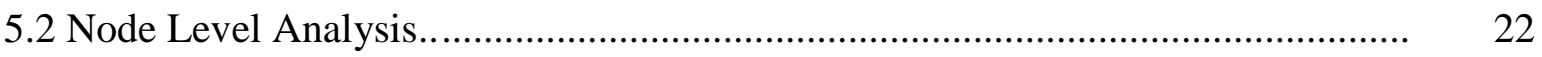

CHAPTER 6 DiSCUSSION .................................................................. 27

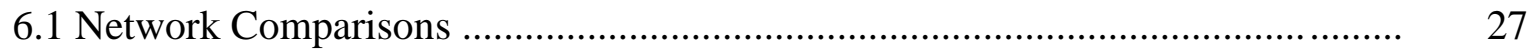

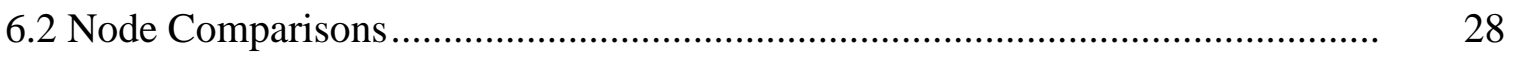

6.3 Limitations and Future Research ........................................................... 29

Chapter 7 CONCLUSIONS AND RECOMMENDATIONS ................................ 31

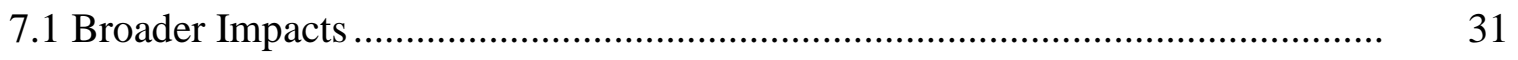

ChAPTER 8 REFERENCES ................................................................ 33 


\section{List of Figures}

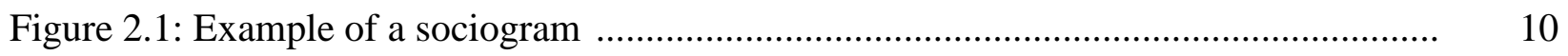

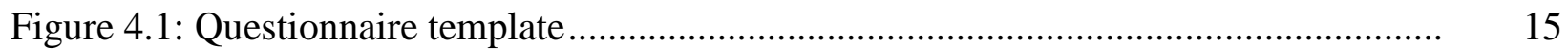

Figure 5.1: Visualization of the mixed-gender networks............................................ 20

Figure 5.2: Frequency, informal, and formal out-closeness ........................................ 23

Figure 5.3: Frequency, informal, and formal in-closeness ........................................... 23

Figure 5.4: Frequency, informal, and formal out-degree .............................................. 23

Figure 5.5: Frequency, informal, and formal in-degree............................................. 23

Figure 5.6: Frequency, informal, and formal betweenness........................................... 24 


\section{List of Tables}

Table 2.1: Females in male dominated occupations (BLS 2014) ................................... 8

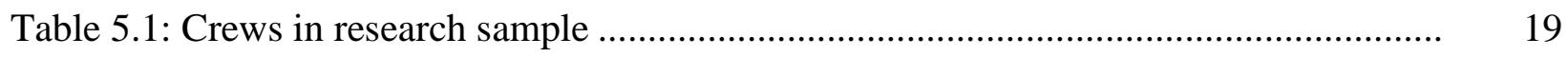

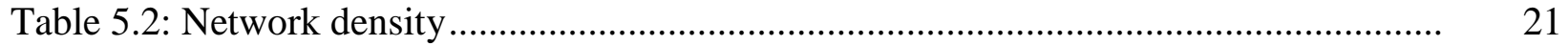

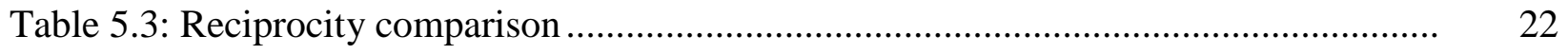

Table 5.4: Nonparametric p-values of male and female centrality parameters ................... 24

Table 5.5: Informal centrality properties of male and female nodes ............................... 25 


\section{Acknowledgments}

This project would not have been possible without the support of the Pacific Northwest Transportation Consortium. We would like to thank the crew members and companies that allowed us to collect these data, as well as Cyndi Lopez, Yanbo Ge, John Wanberg, Rayyan Alasamadani, and Matthew Hallowell for their guidance and support of this project. 


\section{Executive Summary}

This study analyzed the relationships among worker gender, communication patterns, and safety performance on transportation construction (work zones) in Washington state by using Social Network Analysis (SNA). SNA is a tool commonly used to understand and evaluate relationships or ties between people of a certain group, in this case, a crew. Using network parameters such as betweenness (the amount of information routed through an individual), closeness (the distance between individuals), and degree (the number of ties for an individual) (Borgatti et al. 2013), SNA allows for evaluation of both interpersonal communication patterns and total network characteristics. Recent work has identified how worker demographics affect safety communication. Specifically, language and education have been seen to influence the diffusion of safety knowledge in small work crews (Alsamadani et al. 2013a; Fang et al. 2010). Noting the lack of gender diversity among construction workers (US Department of Labor 2010), the research studied how worker gender affects the safety communication patterns of work crews on transportation construction in the Washington State. Considering these past discoveries, the research team hypothesized that work crews with both male and female members (a decrease in work crew homophily) show different communication patterns and worse safety performance than crews without gender diversity.

In order to collect social network data, questionnaires were administered to twenty small (three- to fifteen-person) work crews involved in transportation projects in the Seattle, Wash. Only eight crews were included in the final analysis because of data quality requirements. Crews were part of a convenience sample, as the research team had to be allowed onsite. The research team purposefully selected crews that had both male and female workers. The questionnaire collected demographic data for each individual, including gender, language, years of experience, and job title. Social network data were collected using a form slightly modified from that used in 
Alsamadani et al. (2013b). This form allowed us to capture both the frequency and mode of communication between all persons on the crew.

A centrality analysis of betweenness, closeness, and degree was done for each type of network (frequency, formal, or informal) using UCINET. A non-parametric statistical test showed in-degree and in-closeness to be significantly different for mixed-gender crews in comparison to all-male crews, partially proving our hypothesis. To capture crew level safety performance data, field managers were asked to individually rank (above average, average, below average) their crews' safety attitude and performance in comparison to the company as a whole and to other crews on the jobsite. Unfortunately all the crews sampled were rated as above average or average, and therefore no conclusions were drawn between safety communication patterns and safety performance.

Interestingly, the communication patterns between females and males were found to differ depending on the communication mode. Formal relationships are not as dense as informal communication, and within informal communication (discussions and announcements), females have more reciprocated ties and more female to male ties. A practical implication of these findings are that safety communication patterns for all-male crews differ from mixed-gender crews with respect to density and reciprocity. Within mixed-gender crews, females have fewer incoming ties, and information travelling through the ties must travel a longer distance. This topic requires more research of mixed-gender crews with varying amount of females in order to determine more specifically why the safety communication patterns differ, as well as to compare the safety communication patterns with safety performance. 


\section{Chapter 1 Introduction}

This project begins to address the realities that construction sites are hazardous and male dominated. In 2014, there were 4,821 industry related deaths in the United States. Of those 4, 251 deaths, 1,157 (27 percent) were considered to roadway incidents, and 902 (21 percent) were in construction. In particular, on heavy and civil engineering projects, there were 140 deaths in 2014, of which 78 (56 percent) were due to transportation incidents, making transportation construction one of the most hazardous professions (BLS 2016b). Reducing the number of fatalities and injuries on a jobsite is dependent on strong commitments to safety and proper resources to implement high quality safety programs.

Management characteristics, safety meetings, and safety budget directly affect the safety performance on a jobsite (Jaselskis et al. 1996). However, since safety knowledge management is largely dependent on the type of knowledge and organization, there are many safety knowledge management strategies in construction (Carrillo and Chinowsky 2006; Hallowell 2012). For example, Hallowell (2012) found 11 common methods to transfer safety knowledge. Furthermore, the high performing organizations specifically noted the importance of discussions by which safety knowledge embedded in the crews is transferred to other crew members. In fact, open communication between management and employees allows for more frequent safety discussions and correlates with companies with lower accident rates (Cigularov et al. 2010; Zohar 1980). However, communication patterns are often shaped by demographics.

Furthermore, unlike many safety factors (such as budget, meeting attendance, and trainings) that have directly measurable metrics, safety communication (particularly verbal communication) is more comprehensively represented through networks.

Recent work has identified that worker demographics such as language and education impact how safety knowledge is transferred (Alsamadani et al. 2013b; Fang et al. 2010). 
Theoretically, homophily explains this pattern; homophily is the inclination of people to talk more frequently with people similar to themselves rather than to people with different characteristics (McPherson et al. 2001; Rogers 2003). Therefore, theory suggests that females on jobsites may experience substandard safety communication in the predominately male construction industry. Following this insight and in order to create safe working environments for everyone, this research studied the effect of gender on safety communication.

\subsection{Problem Statement}

We used Social Network Analysis (SNA) to discover how males and females in the trades discuss safety within their own crews on transportation construction sites in Washington state.

\section{$\underline{1.2 \text { Project Goal }}$}

The practical goal of this project was to contribute to improved work zone safety through research. This goal follows the continued effort of PacTrans and the U.S. Department of Transportation to improve safety on transportation construction sites. By describing the gendered structure of safety communication, this research provides a scientific basis for further research on small work crew communication. The practical implication of this research is empirical knowledge that transportation agencies and consultants alike can use to design more effective safety programs and thereby improve work zone safety.

\section{$\underline{1.3 \text { Project Objectives }}$}

In order to accomplish the project goal described above, this research followed five clear objectives:

- collect demographic and social network data from several small work crews in Washington state, 
- draw sociograms (plots of the interpersonal connections) of these networks based on frequency and mode,

- analyze variance (measured as betweenness, closenessness, and degree) between male and female crew members,

- analyze trends among network density and safety performance, and

- develop recommendations and future research based on results.

We hypothesized that work crews with both male and female members (a decrease in work crew homophily) would show different communication patterns and worse safety performance than all-male crews. While we would suspect that all-female crews would perform similarly to the all-male crews, because of construction workforce demographics we were not able to test this hypothesis. 


\section{Chapter 2 Literature Review}

\subsection{Safety Communication}

Communication is the exchange of information. Communication involves the person who initiates the communication, the information communicated, how the information is communicated, to whom the information is sent, and finally the effect the communication has (Lasswell 1948). Communication occurs verbally when people talk in formal meetings or trainings as well as in informal discussions. Written communication is made up of emails, newsletters, reports, posters, and any other type of written material (Vecchio-Sadus 2007).

For the purposes of this study, safety communication was categorized as either formal or informal. Formal communication was defined as established channels that are set up specifically for the exchange of safety information. In construction, formal communication includes information from upper management, written documentation, training, and scheduled toolbox talks. Toolbox talks are meetings that occur before works begins; they are used to increase awareness about certain safety issues and safety conditions onsite (Alsamadani et al. 2013c; Halpin 2006). Upper management plays a vital role in this formal communication and ultimately the safety culture (Abdelhamind and Evertt 2000; Aksorn and Hadikusumo 2008; Choudhry et al. 2009; Hallowell and Gambatese 2009; Sawacha et al. 1999). In contrast, informal communication was defined as impromptu discussions and announcements (Alsamadani et al. 2013c).

The Occupational Safety and Health Administration (OSHA) mandates that all employers train employees on construction sites to recognize and avoid unsafe conditions as well as use any training programs provided (e-CFR 2015). Unfortunately, there is a considerable amount of research showing that training is not always effective (Burke et al. 2011; Mohamed 2002; Zuluaga et al. 2016). Nevertheless, safety communication is an essential tool to a lower safety 
incidents on a jobsite (Jaselskis et al. 1996; Kines et al. 2010; Liao et al. 2014; Vecchio-Sadus 2007). Regardless, to be effective, safety communication must reach everyone on a job site. Unfortunately, and as we tested in this research, there are structural reasons why certain individuals may be less likely to receive safety information.

\subsection{Homophily}

Homophily is the idea that similar people communicate more frequently than do people with different characteristics (McPherson et al. 2001; Rogers 2003). Homophily research began back in the 1920s and 1930s, focusing on both demographic and psychological characteristics. Lazarsfeld and Merton coined the term homophily in 1964 and divided it into (1) statue homophily, which relates to demographic characteristics such as race, age, and gender, and (2) value homophily, which focuses on the internal orientations or beliefs of an individual (Lazarsfeld et al. 1954). Research has shown that the strongest division of characteristics comes from different race and ethnicity, but "age, religion, education, occupation, and gender in roughly that order" (McPherson et al. 2001 p. 415) also affect how people form or dissolve interpersonal connections. On average, as the number of relations between two people increases, homophily also increases (McPherson et al. 2001; Rogers 2003). For example, if persons A and B are at the same school, interested in the same hobbies, and like the same music, it is reasonable likely that persons A and B will have similar demographics. Similarly, if persons C and D have little in common, it is reasonably likely that they have different demographics (i.e., age, occupation, etc).

In this research, we were particularly interested in gender. Gender is different than all other socio-demographic characteristics in that there are almost equal numbers of males and females in the world. Even so, gender homophily - or the presence of just one gender - is often experienced in the workforce, as many occupations are dominated by only one gender. For example, in the United States, females make up 2.9 percent of construction laborers whereas 94.9 
percent of childcare workers are females (BLS 2016a). Having this structural segregation within the profession creates unique relationship challenges for minority members. For example, friendship and support within the workforce tend to be more sex homophilous despite the limited diversity in many occupations (McPherson et al. 2001), possibly resulting in professional isolation of minorities. Ibarra (1992) studied these dynamics influencing social networks and collected supporting evidence that, when controlling for availability, males tend to have more homophilous ties whereas females have heterogeneous ties. Females have ties with males primarily for advancement and with females for friendship. Therefore, even when females are in the minority, gender homophily is not seen in professional female ties, while it was seen in professional male ties (Ibarra 1992).

Recently, homophily has been studied in construction safety research with respect to language (Alsamadani et al. 2013b). Alsamadani and collaborators found that bilingual workers, also called language boundary spanners, have a much more central role in multilingual (speaking English and Spanish) crews' safety communication. Language boundary spanners were found to create an avenue by which crew members who spoke different languages could communicate. Furthermore, this study found that unilingual work crews had safety performance 51 percent higher than that of their multilingual counterparts (Alsamadani et al. 2013b). This past work provides evidence that demographic homophily matters for construction safety communication and performance. As such, in this research we sought to understand how a different kind of demographic minority in construction —females ((9.3 percent) (BLS 2016a)) — experience safety communication.

\section{$\underline{2.3 \text { Females in Construction }}$}

In construction, only 9 percent of the entire workforce is female; in recent years this equates to approximately 800,000 females in construction (Center for Construction Research and 
Training 2013). Table 2.1 shows the more common construction professions and the percentages of females within those trades. The data clearly show that females are in the minority.

Table 2.1: Females in male dominated occupations (BLS 2014)

\begin{tabular}{|l|c|c|}
\hline \multicolumn{1}{|c|}{ Occupation } & $\begin{array}{c}\text { Total Number } \\
\text { of Workers }\end{array}$ & $\begin{array}{c}\text { Percentage } \\
\text { of Females }\end{array}$ \\
\hline Cement masons, concrete finishers, and terrazzo workers & 58,000 & $0 \%$ \\
\hline Crane \& Tower operators & 74,000 & $0.2 \%$ \\
\hline Pipe layers, plumbers, pipefitters, and steamfitters & 564,000 & $1.6 \%$ \\
\hline Carpenters & $1,282,000$ & $1.7 \%$ \\
\hline Operating engineers and other construction equipment operators & 336,000 & $1.8 \%$ \\
\hline Structural Iron and Steel Workers & 52,000 & $2.0 \%$ \\
\hline First line supervisors of construction workers \& extraction trades & 696,000 & $2.4 \%$ \\
\hline Electricians & 769,000 & $2.4 \%$ \\
\hline Construction Laborers & 1,686 & $2.5 \%$ \\
\hline Construction Managers & 711,000 & $7.4 \%$ \\
\hline Architectural and Engineering Managers & 122,000 & $7.6 \%$ \\
\hline Surveying and mapping technicians & 77,000 & $9.7 \%$ \\
\hline Construction and building inspectors & 78,000 & $12.2 \%$ \\
\hline Civil Engineers & 349,000 & $16.5 \%$ \\
\hline
\end{tabular}

Research has shown that there are many barriers preventing females from entering the construction field. The most common are (1) the cultural image of tough men, foul language, and adversarial relationships, (2) lack of knowledge about career opportunities within construction, particularly for young students, (3) the balance between work and family, and (4) informal and unstructured opportunities for training and advancement (Amaratunga et al. 2006). 
For those females who do enter the field, they are often to subject to harassment, assault and other unhealthy or unsafe situations (Amaratunga et al. 2006; Ericksen and Schultheiss 2009). Other unique female safety concerns include but are not limited to lack of fitted personal protection equipment (PPE), poor sanitation facilities, and psychological stresses associated with being in a male dominated field (Goldenhar and Sweeney 1996). While ill-fitting PPE has known repercussions in terms effectiveness and has recently been linked to job satisfaction (Wagner et al. 2013), the effect of these barriers on females' job site safety represents a significant gap in the literature. Beyond these established issues for the safety of females on construction job sites, there is no research that studies how females' demographic minority status may impact the flow of construction safety knowledge and therefore their safety. This research contributes to this gap in the literature.

\subsection{Social Networks}

\subsubsection{Theory}

Social Network Analysis (SNA) dates back to at least 1934 when the technique was used as a formal way of presenting interpersonal relationships (Freeman 2004). Within SNA, relationships are mapped as sociograms that can be mathematically evaluated by using graph theory. A fundamental assumption of social networks is that structure matters. The same set of people with different relationships perform very differently (Borgatti et al. 2009). Engineering and construction projects are unique social networks because of the fluidity with which they form and dissolve. Most previous SNA research in construction has focused on relationships and knowledge management between different firms or relationships within firms (Chinowsky et al. 2010; Pryke 2012). However, recently SNA has been used to study small work crew communication patterns (Alsamadani et al. 2013c; Fang et al. 2010). This past research has shown that language changes the dissemination of information among work crews (Alsamadani 
et al. 2013b); and that education and experience change how workers ask for and share safety information (Fang et al. 2010).

\subsubsection{Network Characterization}

Sociograms are made up of nodes and ties, as can be seen in figure 2.1. Typically, people, organizations, or other agents are the nodes, and the lines called ties represent relationships and communication. Ties can be directed or undirected. Directed ties indicate that the relationship goes a certain direction (i.e., information goes from A to B, but not from B to A). If the relationships in a network go both ways (i.e., membership in a certain club), then the ties are considered undirected (Borgatti et al. 2013).

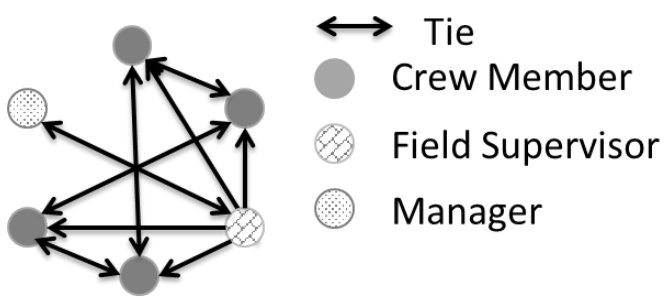

Figure 2.1: Example of a sociogram

Networks can be analyzed by comparing different networks, or by internally comparing relations within a network. When comparing networks, density (the proportion of ties that exist over all potential ties), reciprocity (the number of undirected ties), transitivity (the number of relationships that are in groups of three or clusters), and other network properties are useful descriptors of the network (Borgatti et al. 2013). These properties characterize the network with a single value that is useful when comparing those properties to network outputs such as productivity, cost efficiency, and safety performance. In other words, each network has one density, reciprocity, and transitivity characteristic, whereas centrality indictors are unique to each node. Centrality describes a node's position within the network. The number of centrality 
measures for each network is therefore dependent on the number of nodes. There are many centrality measures; however, for purposes of this report only betweenness, closeness, and degree are presented. First, betweenness is related to the number of times a particular node is caught between the shortest tie between two other nodes. It is expressed as a portion of the number of shortest paths between two nodes that the particular node falls in over the total number of shortest paths connecting the two nodes. The minimum betweenness for a node is zero (when it is not in the shortest path of any two nodes) and the maximum is one (when it is along every shortest path). Second, closeness centrality is the measure of a node's ability to get information through other nodes and is typically thought of as the time it takes to spread or receive information (Borgatti et al. 2009). It is an inverse measure of centrality because the closest node is the one with the smallest closeness measure. However, typically closeness scores are divided by one minus the number of nodes in the network in order to create a series of closeness values in which the highest values are the closest. It is directionally measured as in-closeness, the sum of geodesic distances for all ties coming into the node, and out-closeness, the sum of geodesic distances leaving the node to all others (Borgatti et al. 2013). Geodesic distance in social networks is the number of ties in the shortest possible path between two nodes (Hanneman and Riddle 2005). Finally, degree centrality is a count of the number of ties connected to a node. Therefore, in-degree is amount of ties coming into a node and out-degree for that node is the number of ties going out (Borgatti et al. 2009). 


\section{Chapter 3 Study Data}

This study specifically focused on construction crews working in Washington state on transportation construction projects including highways, rails, and bridges. Only transportation construction projects were included in this project in order to limit the number of variances in jobsite safety hazards (Gambatese et al. 1997; Hinze and Godfrey 2003). The participants were selected as a part of a convenience sample. SNA required that an entire crew fill out the survey, meaning that the entire crew had to be present when the survey was distributed. We selected crews with both male and female workers and little language diversity, as language diversity is known to affect safety communication (Alsamadani et al. 2013b). Questionnaires were distributed to 20 crews; however, because of data quality requirements, twelve crews were dropped from the final analysis. Ultimately, eight construction crews containing between five to eleven members were analyzed. Three of these eight crews had female members, allowing us to compare work crews with and without gender diversity. We acknowledge and value the presence of other genders in construction, but to our knowledge our data collection did not include members of those populations. Table 2 in Chapter 5 shows the attributes of the crews retained for analysis. 


\section{Chapter 4 Methodology}

In order to collect safety communication patterns within small work crews, the research team used a modified version of a questionnaire developed by Alsamadani et al (2013a). The questionnaire began with general demographic questions including age, gender, language preference, and years in construction, the trade, and with their current company. The final two pages of the questionnaire were tables as shown figure 4.1. The first table asked the participant to think about when they provided safety information to other crew-members. It asked them to estimate how often (never, monthly, bi-weekly, weekly, daily, and more than once daily) as well as in what mode (written, training, toolbox talk, discussion, or announcement). The final columns asked for the purpose of the communication (new information or providing feedback).

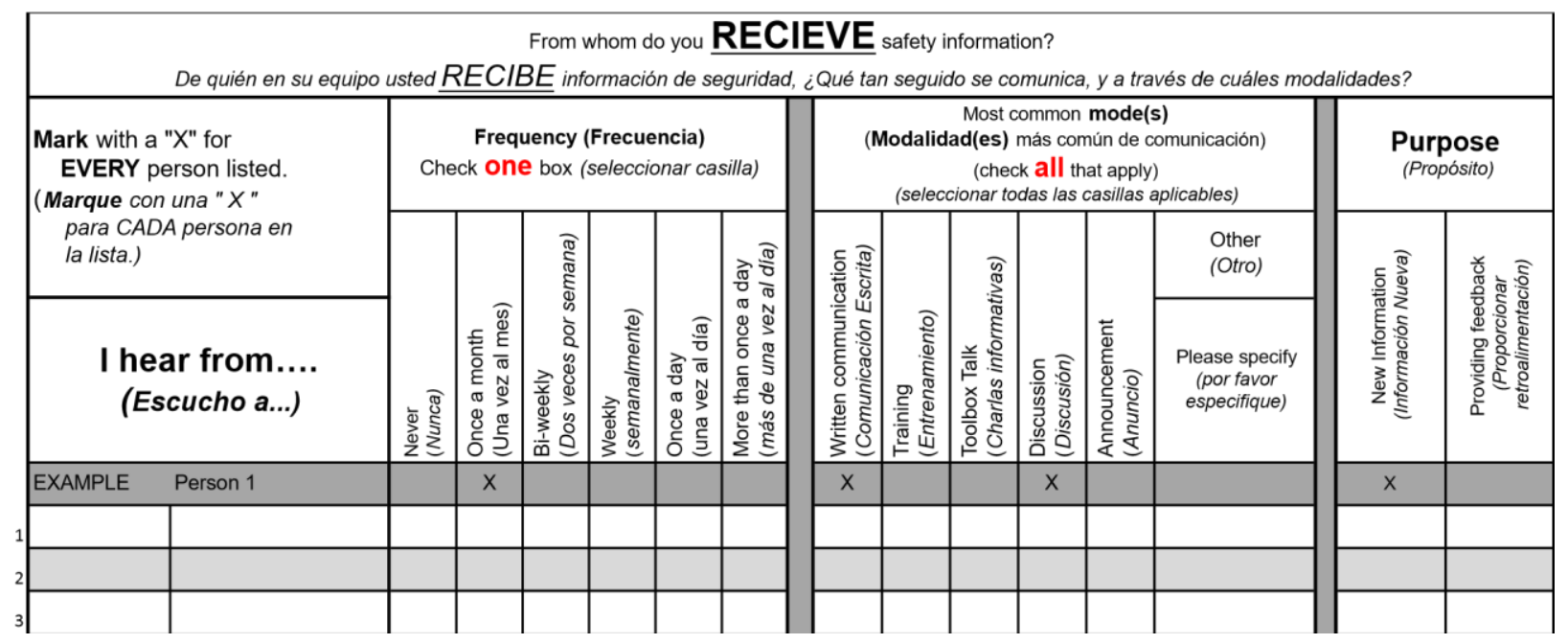

Figure 4.1: Questionnaire template

In order to facilitate data collection of a complete network, prior to the questionnaire distribution, the research team obtained the names of everyone on the crew and pre-populated the questionnaire. The questionnaire was distributed to participants in paper form in both Spanish and English. Typically the crew members were given the questionnaire after their "stretch and flex" and prior to starting work. "Stretch and flex" is a commonly used term to describe a time when the 
entire crew stretches to reduce the risk of injury (Choi and Rajendran 2014). Crew members took between 10 and 15 minutes to fill out the survey. After the crews had completed the questionnaires, the research team asked the field manager to rate (below average, average, and above average) the crews under their supervision and to provide the recordable injury rate from the previous year for their company.

In order to create social networks, the data were transformed into three adjacency matrices (frequency, formal, and informal). The rows and columns of an adjacency matrix are the nodes, and the data within the matrix are the ties (Borgatti et al. 2013). All connections were recorded as binary; therefore, ties were represented as either a one or zero. When a tie was recorded by either of the people associated with it, it was assumed to exist. For example, if person A documented sharing information with person B weekly via email, a connection was assumed to exist even if node B did not mark receiving the email weekly. This assumption was made because of the large recall requirement associated with SNA questionnaire. Similarly, if a person was absent during the day of the study, that person was modeled as having symmetric ties as reported by other crew members. All crews had fewer than two absentees.

Frequency, formal, and informal matrices for each crew were imported into UCINET, an open source social network analysis software, for each crew. The frequency network showed the total amount of communication between people, while formal communication networks were the accumulation of written, training, and toolbox talks. The informal networks included both discussion and announcement communication. Within UCINET, the network visualizations (figure 1) were created by using NetDraw and R. For each network, the density was calculated as a single parameter to describe the network. To capture crew level safety performance data, field managers were asked to rank (above average, average, below average) their individual crew's safety attitude in comparison to those of the company and to other crews on the jobsite. 
This safety information was used (1) to compare crews from the same company, (2) to understand the crew's relative safety performance with respect to other companies in the study, and (3) to analyze relationships between safety performance and network density.

In order to determine whether females were located in a different network position than males, the research team calculated three different types of centrality (betweenness, closeness, and degree) for each type of network. Consequently, for any given node, nine centrality parameters were calculated, three parameters for each type of network (frequency, formal, and informal). All of these values were calculated within UCINET. These values were statistically compared by using a nonparametric Mann-Whitney test. Because of the interdependent nature of the social networks, the statistical analysis was run only on the centrality parameters for nodes within the mixed gender crews. The research team chose not to compare the centrality parameters for males in all-male crews to nodes in the mixed-gender crews because those male nodes did not have the potential to communicate with females about safety. Therefore, the nonparametric test compared the centrality metrics for only the males and females in mixedgender crews.

By calculating density and reciprocity for the networks as a whole, the research team was able to compare all-male networks to mixed-gender networks. The cohesion or density of the networks was calculated as the portion of existing ties over all potential ties. In a directed network, the total number of ties is equal to the number of nodes multiplied by the one less than the number of nodes in the network. The density of a directed network is therefore shown in equation 4.1, where $\mathrm{n}$ is the number of nodes in the network (Borgatti et al. 2013).

$$
D=\frac{\# \text { of ties }}{n(n-1)}
$$


Reciprocity is particularly interesting when using directed networks. This parameter shows the extent to which each network has information traveling both to and from any given node. Arc reciprocity is the proportion of all ties that are reciprocated over the total number of ties, whereas dyad reciprocity is the proportion of dyads (pairs of nodes) that are symmetric. For a dyad to be symmetric, the pairs must either both reciprocate the tie or both choose not to reciprocate the tie (Borgatti et al. 2013). UCINET calculates reciprocity with the formulas below (Borgatti et al. 2002).

$$
\begin{aligned}
& \text { Dyad Reciprocity }=\stackrel{R}{\stackrel{R}{(R+2 U)}}
\end{aligned}
$$

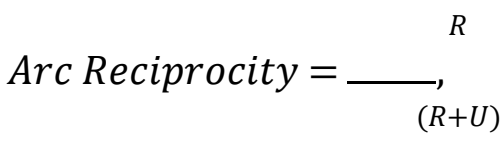

where $R$ is the number of reciprocated arcs and $U$ is the number of unreciprocated arcs. 


\section{Chapter 5 Results}

\section{$\underline{5.1 \text { Network-Level Analysis }}$}

As shown in table 5.1, eight crews were included in this study. All crews worked in the Seattle area on transportation construction projects. The largest crew had eleven members, while the smallest crew had five. Only three crews $(3,4$, and 5) were mixed gender. In fact, crew 3 and crew 4 only had one female, while crew 5 had two females. The crews included laborers, electricians, and carpenters. The safety performance of seven of the eight crews was rated as above average by each crew's superintendent or safety manager; the remaining average crew was an all-male crew. All the crews worked for companies with low recordable incident rates (RIR) or experience medication factors (EMR), suggesting that a strong safety culture was present throughout the companies. Figure 5.1 shows the network visualizations of the mixed-gender crews made with NetDraw.

Table 5.1: Crews in research sample

\begin{tabular}{|c|c|c|c|c|c|c|c|c|}
\hline & \multicolumn{9}{|c|}{ Crews } \\
\cline { 2 - 10 } & $\mathbf{1}$ & $\mathbf{2}$ & $\mathbf{3}$ & $\mathbf{4}$ & $\mathbf{5}$ & $\mathbf{6}$ & $\mathbf{7}$ & $\mathbf{8}$ \\
\hline Number of Members in Crew & 5 & 6 & 9 & 7 & 9 & 6 & 6 & 11 \\
\hline Number of Females & 0 & 0 & 1 & 1 & 2 & 0 & 0 & 0 \\
\hline Nonresponse & 1 & 2 & 1 & 0 & 0 & 1 & 1 & 1 \\
\hline Bilingual & 0 & 2 & 0 & 0 & 0 & 2 & 3 & 2 \\
\hline Spanish Only & 0 & 0 & 0 & 0 & 0 & 0 & 0 & 2 \\
\hline Average Age & 44 & 47 & 36 & 47 & 31 & 35 & 36 & 45 \\
\hline Average \# Yrs in Construction & 18 & 19 & 14 & 23 & 6 & 11 & 11 & 13 \\
\hline Average \# Yrs in Trade & 20 & 15 & 9 & 19 & 6 & 9 & 10 & 7 \\
\hline
\end{tabular}




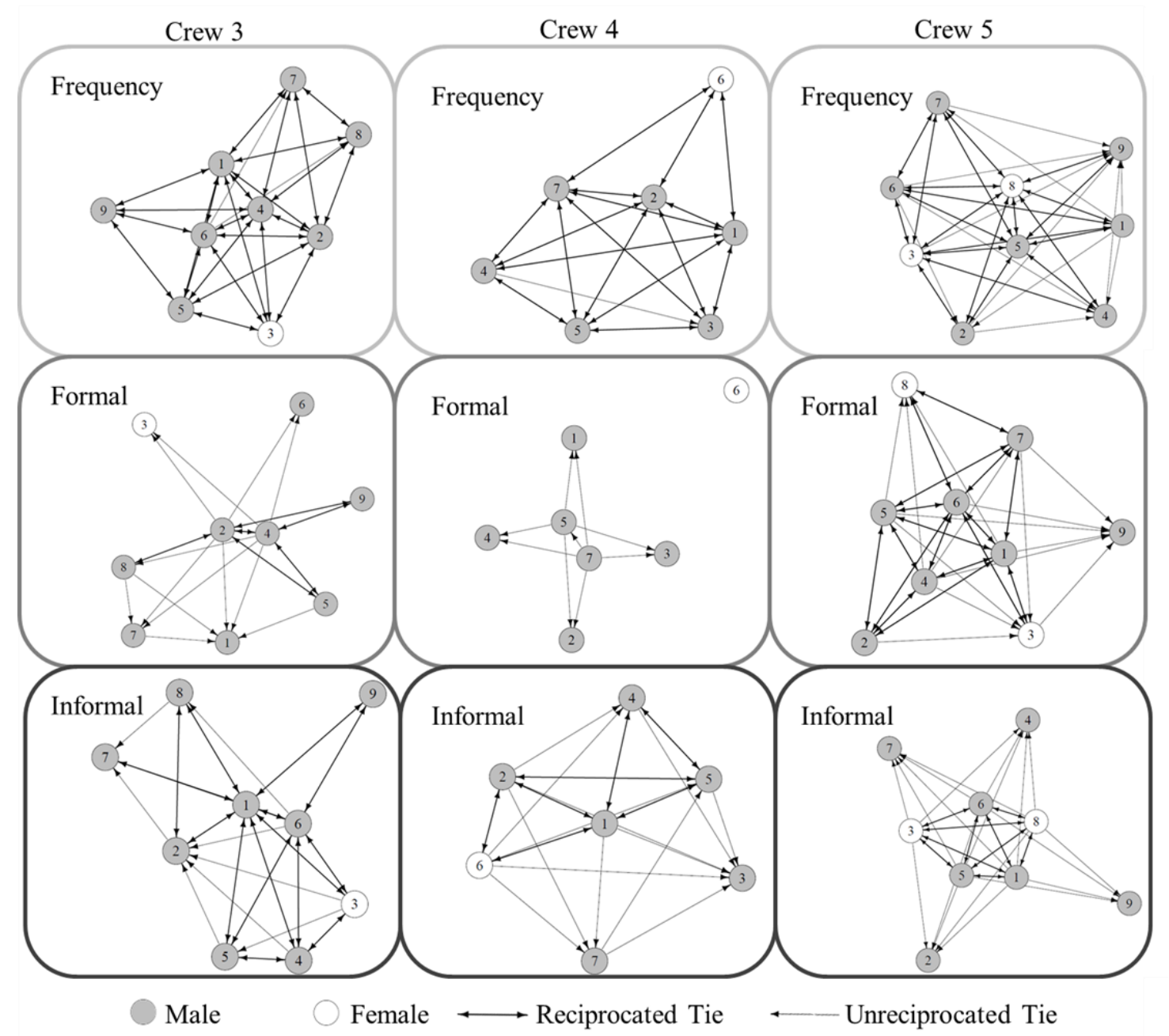

Figure 5.1: Visualization of the mixed-gender networks

Table 5.2 shows the average densities of the all-male crews $(1,2,6,7$, and 8$)$ and the mixed-gender crews $(3,4$, and 5). The network density for the all-male and mixed-gender crews was approximately the same for the frequency communication networks (0.82 vs 0.79$)$.

However, the mixed-gender crews had a higher average informal density and a lower average formal network density. This means that there were more informal connections in mixed-gender crews than in all-male crews, while there were more formal connections in the all-male crews.

Table 5.2: Network density \begin{tabular}{ll|l} 
Averages $\quad$ All Male & Mixed Gender
\end{tabular} 


\begin{tabular}{ll|l} 
Network Density & 0.82 & 0.79 \\
\hline Formal Network Density & 0.61 & 0.41 \\
\hline Informal Network Density & 0.44 & 0.58 \\
\hline
\end{tabular}

Focusing on the directed nature of the data, the all-male and mixed-gender crews showed similar values for arc (proportion of reciprocated ties) and dyad reciprocity (proportion of symmetric pairs in a network) in the informal networks ( 0.42 vs 0.44$)$ and frequency networks (0.84 vs 0.94$)$, as shown in table 5.3 . The node reciprocity varied with the formal communication network for both arc reciprocity ( 0.72 vs 0.43$)$ and dyad reciprocity ( 0.48 vs 0.31 ), indicating that there were fewer reciprocated ties and similarly fewer symmetric pairs in the mixed-gender crews than in the all-male crews. In practice, this means that in all-male crews, the male-to-male dyads were more commonly symmetric than dyads in the mixe- gender crews. This means that for formal networks the all-male crews had more connections that were countered, implying more discussions in which both males on a tie communicated back and forth; whereas in the mixed-gender crews, the formal communication was more one-sided. To a lesser extent, the reverse can be seen in the arc reciprocity ( $0.54 \mathrm{vs} 0.60)$ and dyad reciprocity (0.42 vs 0.44$)$ for the informal networks. In the informal networks, the mixed-gender crews reciprocated more with informal ties than in the all-male crews. In other words, the informal relationships within all-males crews were directed or one-way more often than in the mixedgender crews. 
Table 5.3: Reciprocity comparison

\begin{tabular}{|c|c|c|c|}
\hline & & All-Male & Mixed-Gender \\
\hline \multirow{3}{*}{$\stackrel{0}{\gtrless}$} & Frequency & 0.97 & 0.91 \\
\hline & Formal & 0.72 & 0.43 \\
\hline & Informal & 0.54 & 0.60 \\
\hline \multirow{3}{*}{ 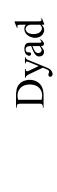 } & Frequency & 0.94 & 0.84 \\
\hline & Formal & 0.48 & 0.31 \\
\hline & Informal & 0.42 & 0.44 \\
\hline
\end{tabular}

\section{$\underline{5.2 \text { Node Level Analysis }}$}

For each node within a network, three different centrality parameters were calculated:

closeness, degree, and betweenness. Since the data collected were directed, closeness and degree were further broken into in-closeness, out-closeness, in-degree, and out-degree. Therefore, five centrality parameters were calculated within the three different networks made for each crew.

Figures 5.2 - 5.6 show the distribution of out-closeness, in-closeness, out-degree, in-degree, and betweenness for every node in the frequency, informal, and formal networks. All the calculated parameters were normalized within the network in order to enable comparisons between the crews. For example, since in-degree is simply the number of ties that are coming into a node, it is normalized by dividing by the largest possible degree (one less the number of nodes) in that network. These distributions include all nodes in all crews; therefore, there are four females and 55 males represented in each figure. 


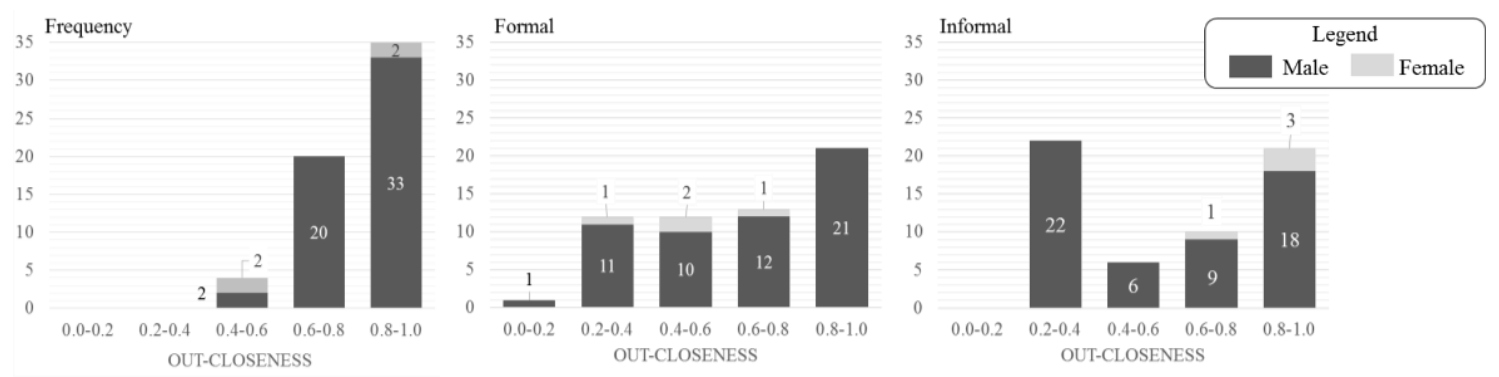

Figure 5.2: Frequency, informal, and formal out-closeness

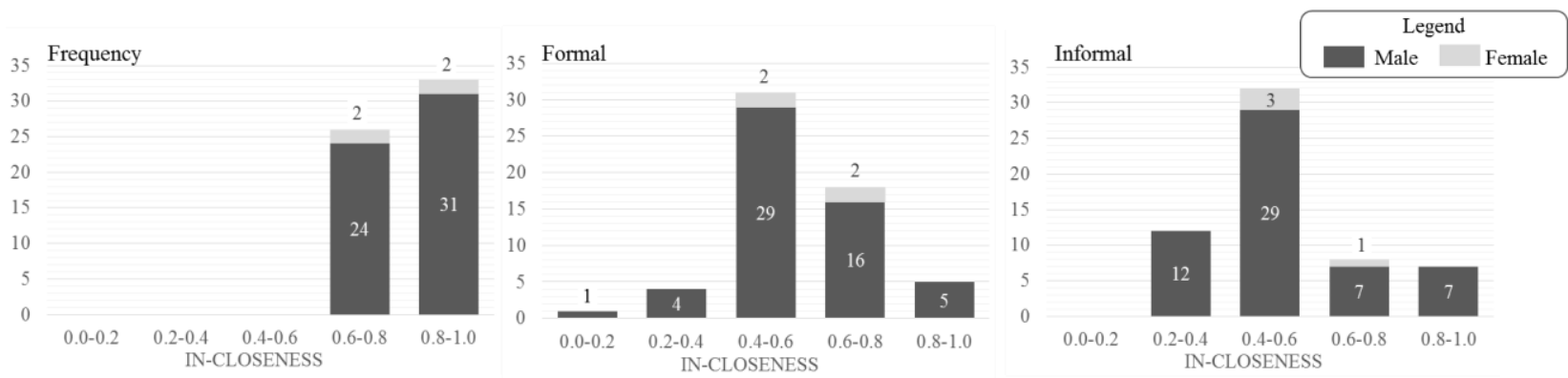

Figure 5.3: Frequency, informal, and formal in-Closeness

Figure 5.4: Frequency, informal, and formal out-degree

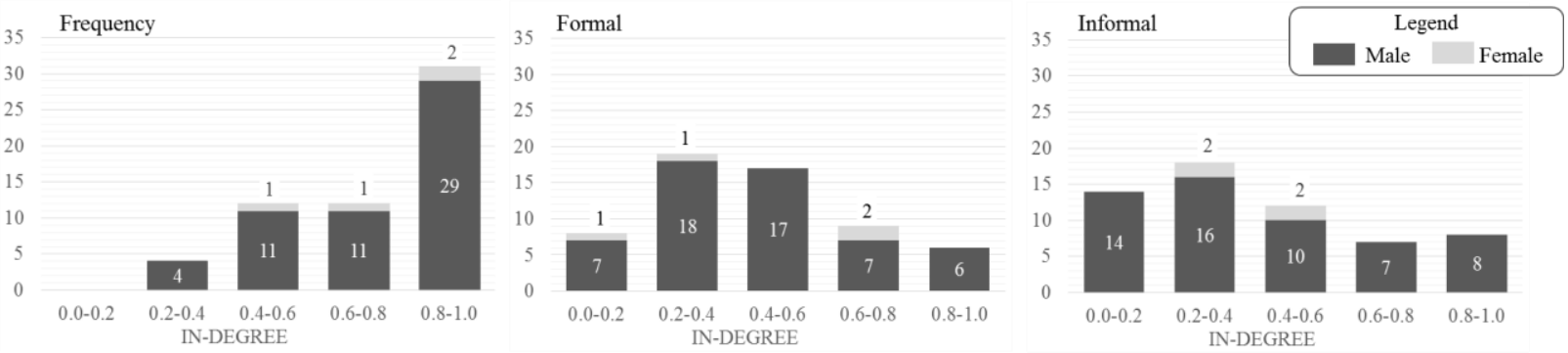

Figure 5.5: Frequency, informal, and formal in-degree 

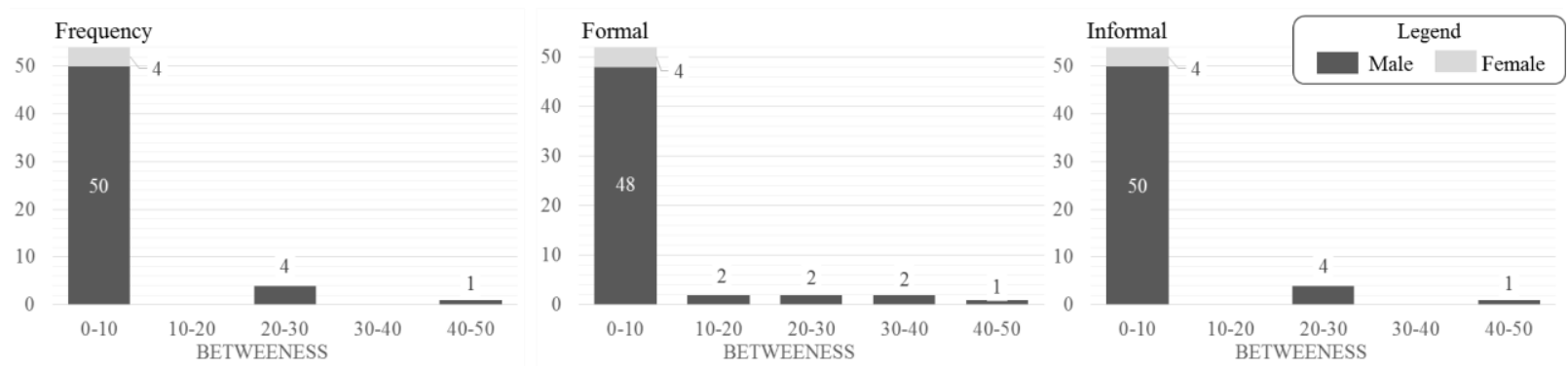

Figure 5.6: Frequency, informal, and formal betweenness

The five centrality parameters for the nodes in the mixed-gender networks (Crews 3, 4, 5) were statistically analyzed by using a non-parametric test, since the number of male and female nodes were uneven and non-normal. Only the mixed-gender crews were included in this analysis because centrality parameters are dependent on the composition of the group; therefore, the allmale crews did not have the same variation with respect to females as the mixed-gender crews. Therefore, the sample that was statically analyzed includesd 21 males and four females. Table 5.4 shows that males and females within the mixed-gender crews did not have significantly different centrality parameters in the frequency and formal networks. However, in the informal networks, females had significantly $(\mathrm{p}<0.05)$ lower amounts of in-degree and in-closeness, as can be seen in table 5.5. Male in-closeness and in-degree were both larger than those of the females in the mixed-gender networks.

Table 5.4: Nonparametric $p$-values of male and female centrality parameters

\begin{tabular}{|l|c|c|c|}
\hline \multicolumn{1}{|c|}{ Mann-Whitney } & Frequency & Formal & Informal \\
\hline Out-Closeness & 1.00 & 0.24 & 0.15 \\
\hline In-Closeness & 0.70 & 0.79 & $0.05^{* *}$ \\
\hline Out-Degree & 1.00 & 0.22 & 0.15 \\
\hline In-Degree & 1.00 & 0.91 & $0.04^{* *}$ \\
\hline Betweenness & 0.64 & 0.56 & 0.31 \\
\hline
\end{tabular}

** Indicates a significance of less than 0.05 
Table 5.5: Informal centrality properties of male and female nodes

\begin{tabular}{|l|c|c|c|}
\hline & $\begin{array}{c}\text { Male } \\
(\mathbf{n = 2 1})\end{array}$ & $\begin{array}{c}\text { Female } \\
(\mathbf{n = 4})\end{array}$ & Difference \\
\hline Out-Closeness & 0.68 & 0.90 & -0.22 \\
\hline In-Closeness & 0.64 & 0.52 & $0.12^{* *}$ \\
\hline Out-Degree & 0.51 & 0.88 & -0.36 \\
\hline In-Degree & 0.60 & 0.43 & $0.17^{* *}$ \\
\hline Betweenness & 2.08 & 0.06 & 2.02 \\
\hline
\end{tabular}

** Indicates a significance of less than 0.05 


\section{Chapter 6 Discussion}

\section{$\underline{6.1 \text { Network Comparisons }}$}

Since previous research has indicated that crews with denser social networks have improved hazard recognition (Albert and Hallowell 2014), it is important to consider network density. In this study, mixed-gender crews had approximately the same density as all-male crews in the frequency networks, as shown in table 5.2. However, in the formal networks, which include training, toolbox talks, and official correspondence (email, letters, etc), all-male crews had a higher density than the mixed-gender crews. This implies that all-male crews rely more heavily on formal safety communication methods than the mixed-gender crews. Conversely, the mixed-gender crews showed higher density within the informal safety communication networks; therefore, the mixed-gender crews rely more heavily on informal communication for their safety information. However, it is important to note that while the network as a whole may have a higher density, all nodes do not equally contribute to the density. In fact, the centrality parameters showed that females are not equally involved in the informal networks, as is explained in more detail below.

The dyad and arc reciprocity data confirmed a difference between the formal networks of the all-male and mixed-gender crews. In the formal networks, approximately 72 percent of the male-to-male ties were reciprocated, whereas only 43 percent of ties in the mixed-gender crews were reciprocated. Therefore, assuming all ties carry equal amount of information, in all-male crews 70 percent of the information travels both ways, whereas in a mixed-gender crew the majority of information is spread only in one direction (male to female). In another quantifiable difference between mixed- and all-male gender crews, the data showed that in a mixed-gender group males ask fewer questions in a formal setting than they would in an all-male group. Since females tend to ask fewer questions in mixed-gender settings, this reduces the total amount of 
formal safety communication available for all workers. A follow-up study should look at allfemale crews to determine whether the amount of formal safety communication changes, as this study was unable to find any all-female crews. Therefore, as foremen, superintendents, and safety managers encounter mixed-gender crews, they should encourage questions in formal settings to make sure that crew members have all the information they need to safely complete tasks.

\section{$\underline{6.2 \text { Node Comparisons }}$}

Instead of depending on formal safety communication, the questions were shifted to an informal setting, where our data showed females to be at a disadvantage for receiving safety information. Specifically, the centrality parameter analysis showed that females are not equally involved in the informal networks. For example, the centrality parameters calculated for each node showed the male and female in-degree and in-closeness parameters for the mixed-gender crews were statistically significantly different. In both cases, the male parameter averages were higher than the females. In fact, the male nodes had 17 percent more ties coming in than the females. While it is possible that the females were getting all the necessary safety information (the content and effectiveness of ties were not measured in this study), the reduced number of incoming ties would decrease the channels by which the information could be received by the females. Furthermore, the females had 12 percent less in-closeness. Since in-closeness is commonly thought of as the time it takes for information to get to a particular node, and these females have 12 percent less in-closeness, they would receive safety information in 12 percent more time than would their male counterparts.

There are many potential reasons why females have fewer incoming ties and receive safety information more slowly than the males in the crew. In this research, we framed this observed difference through the principle of homophily. As described in the literature review, 
homophily means that people generally tend to feel comfortable talking to people similar to themselves (McPherson et al. 2001; Rogers 2003). Regardless of the complexities behind gender dynamics, however, the data presented here contribute clear evidence that safety information does not reach all individuals in a work crew at the same time, in the same amounts, or by the same avenues.

\subsection{Limitations and Future Research}

There are few females working in the skilled construction trades, making finding crews challenging; this limited the number of crews we could include and was a key limitation of our study. In addition, we were not able to locate or study all-female crews and cannot therefore make claims regarding communication in these settings. As such, more social network data from mixed-gender crews is needed to be able to generalize these findings to a larger population. A second key limitation, common to much social network research, is the difficultly in recalling and recording verbal communications; this was unavoidable given the nature of construction work (Menon et al. 1995). A related challenge with social network analysis is that the entire crew should take the questionnaire; this was difficult given the fluid nature of the construction project crews.

Finally, this research was unable to associate safety performance with the safety communication data. The crews sampled were too similar in safety performance, perhaps because poor performance contexts were less willing to host the research team. Therefore, we cannot contribute to the body of knowledge regarding the link between safety communication and safety performance. Future studies should connect the communication patterns with the safety performance of the crew.

In order to overcome the limitations of this study, future research should collect more social network data on small work crew safety communication. The research team should look 
for single language crews with multiple females. More network data will help determine how generalizable these results are. Furthermore, the research team should observe the crews and the hazards surrounding them in order to triangulate the data being collected. This study was the first of its kind to look at how females affect safety communication in the field. As the construction industry continues to aim for zero injuries, this type of research is essential and will continue to be until the goal of zero injuries becomes a reality. 


\section{Chapter 7 Conclusions and Recommendations}

This research collected all-male and mixed-gender social network data for eight small construction crews on transportation jobsites in Washington state. The communication data collected provides insight into network and node level characteristics of males and females in the sample data. At the network level, the data showed that all-male crews have considerably more formal communication than mixed-gender crews, and the mixed-gender crews have considerably more informal communication. Comparison of node-level parameters (betweenness, closeness, and degree) in the mixed-gender crews showed that females in informal networks have statistically fewer in-coming ties than males, and information coming through those ties comes at a slower rate (in-closeness). The broader impacts of these results and recommendations for future research that can build upon them are discussed below.

\section{$\underline{7.1 \text { Broader Impacts }}$}

As construction is one of the most dangerous professions in the U.S. and safety communication is an essential part of a safety program, this research contributes to the literature in two significant ways. First, formal safety communication relationships are not a dense as informal safety communication networks on transportation construction sites within mixedgender crews. In fact, the all-male crews have a denser formal network than informal network. While this research could not associate these differences with safety performance, this research does show that mixed-gender crews communicate differently than all-male crews. In particular, females tend to ask fewer questions than the formal network's average (shown in figure 5.1), meaning that future research should determine how safety programs can be adapted in order to accommodate mixed-gender crews.

Second, we saw that in informal networks, females have fewer in-coming ties (shown in table 6) than the all-male informal communication networks. While the females hadve more 
informal ties that are reciprocated or female to male, the information traveling through male incoming ties take longer to reach females, as measured by in-closeness, and there are fewer incoming ties, as measured by in-degree. This suggests that females receive safety information slowly, and that females receive less informal (tacit) safety knowledge than males in the crew. Previous research has shown that the transfer of tacit safety knowledge is important in achieving high safety performance (Hallowell 2012). Therefore, this research contributes that in mixedgender crews, gender should also be considered in knowledge management and transfer. On a construction site everyone needs to have equal and quick access to all safety information in order to prevent accidents. Since safety is embedded into the success of all construction projects, construction research should continue to focus on gendered communication and how to foster a safe and productive project site. 


\section{Chapter 8 References}

Abdelhamind, T., and Evertt, J. G. (2000). "Identifying Root Causes of Construction Accidents." Journal of Construction Engineering and Management, 126(1), 52-60.

Aksorn, T., and Hadikusumo, B. H. W. (2008). "Critical success factors influencing safety program performance in Thai construction projects." Safety Science, Construction Safety, 46(4), 709-727.

Albert, A., and Hallowell, M. (2014). "Modeling the Role of Social Networks in Situational Awareness and Hazard Communication." Construction Research Congress 2014, American Society of Civil Engineers, 1752-1761.

Alsamadani, R., Hallowell, M., Javernick-Will, A., and Cabello, J. (2013a). "Relationships among Language Proficiency, Communication Patterns, and Safety Performance in Small

Work Crews in the United States." Journal of Construction Engineering and Management, 139(9), 1125-1134.

Alsamadani, R., Hallowell, M., Javernick-Will, A., and Cabello, J. (2013b). "Relationships among Language Proficiency, Communication Patterns, and Safety Performance in Small Work Crews in the United States." Journal of Construction Engineering and Management, 139(9), 1125-1134.

Alsamadani, R., Hallowell, M., and Javernick-Will, A. N. (2013c). "Measuring and modelling safety communication in small work crews in the US using social network analysis." Construction Management \& Economics, 31(6), 568-579.

Amaratunga, R. D. G., Haigh, R. P., Shanmugam, M., Lee, A. J., and Elvitigalage Dona, N. G. (2006). "Construction industry and women: A review of the barriers." Proceedings of the 3rd International SCRI Research Symposium. BLS. (2014). "Nontraditional Occupations."

BLS. (2016a). "Employed persons by detailed occupation, sex, race, and Hispanic or Latino ethnicity." Labor Force Statistics from the Current Population Survey, <http://www.bls.gov/cps/cpsaat11.htm> (Oct. 10, 2016).

BLS. (2016b). "Census of Fatal Occupational Injuries: TABLE A-1. Fatal occupational injuries by industry and event or exposure, all United States, 2014." U.S. Department of Labor. Borgatti, S. P., Everett, M. G., and Freeman, L. C. (2002). Ucinet of Windows: Software for Social Network Analysis. Analytic Technologies, Havard, MA.

Borgatti, S. P., Everett, M. G., and Johnson, J. C. (2013). Analyzing Social Networks. SAGE Publications Ltd, Los Angeles i.e. Thousand Oaks, Calif.; London.

Borgatti, S. P., Mehra, A., Brass, D. J., and Labianca, G. (2009). "Network Analysis in the Social Sciences." Science, 323(5916), 892-895. 
Burke, M. J., Salvador, R. O., Smith-Crowe, K., Chan-Serafin, S., Smith, A., and Sonesh, S. (2011). "The dread factor: How hazards and safety training influence learning and performance." Journal of Applied Psychology, 96(1), 46-70.

Carrillo, P., and Chinowsky, P. (2006). "Exploiting Knowledge Management: The Engineering and Construction Perspective." Journal of Management in Engineering, 22(1), 2-10.

Center for Construction Research and Training. (2013). The Construction Chart Book: The U.S. Construction Industry and Its Workers.

Chinowsky, P. S., Diekmann, J., and O’Brien, J. (2010). "Project Organizations as Social Networks." Journal of Construction Engineering and Management, 136(4), 452-458.

Choi, S. D., and Rajendran, S. (2014). “Construction workers' perception of stretch and flex program effectiveness in preventing work-related musculoskeletal disorders." Proceedings of the XXVI Occupational Ergonomics and Safety Conference.

Choudhry, R., Fang, D., and Lingard, H. (2009). "Measuring Safety Climate of a Construction Company." Journal of Construction Engineering and Management, 135(9), 890-899.

Cigularov, K. P., Chen, P. Y., and Rosecrance, J. (2010). "The effects of error management climate and safety communication on safety: A multi-level study." Accident Analysis \& Prevention, Safety Climate: New Developments in Conceptualization, Theory, and Research, 42(5), 1498-1506.

Daniel W. Halpin. (2006). Construction management. Wiley, Hoboken, NJ. e-CFR: Title 29: Labor PART 1926-SAFETY AND HEALTH REGULATIONS FOR CONSTRUCTION Subpart C-General Safety and Health Provisions. (2015). Electronic Code of Federal Regulations.

Ericksen, J. A., and Schultheiss, D. E. P. (2009). "Women Pursuing Careers in Trades and Construction." Journal of Career Development, 36(1), 68-89.

Fang, D., Huang, J., and Fong, P. S. W. (2010). "Sharing Construction Safety Knowledge through Social Networks.” Salford, UK.

Gambatese, J. A., Hinze, J. W., and Haas, C. T. (1997). "Tool to Design for Construction Worker Safety.” Journal of Architectural Engineering, 3(1), 32-41.

Goldenhar, L., and Sweeney, M., (1996) “Tradewomen's Perspectives on Occupational Health and Safety: A Qualitative Investigation.” American Journal of Industrial Medicine, 29(5), 516-520.

Hallowell, M., and Gambatese, J. A. (2009). “Construction Safety Risk Mitigation.” Journal of Construction Engineering and Management, 135(12), 1316-1323.

Hallowell, M. R. (2012). "Safety-Knowledge Management in American Construction Organizations.” Journal of Management in Engineering, 28(2), 203-211. 
Hanneman, R. A., and Riddle, M. (2005). Introduction to Social Network Methods. University of California, Riverside, Riverside CA.

Hinze, J., and Godfrey, R. (2003). "An evaluation of safety performance measures for construction projects." Journal of Construction Research, 4(1), 5-15.

Ibarra, H. (1992). "Homophily and Differential Returns: Sex Differences in Network Structure and Access in an Advertising Firm." Administrative Science Quarterly, 37(3), 422-447.

Jaselskis, E. J., Anderson, S. D., and Russell, J. S. (1996). "Strategies for Achieving Excellence in Construction Safety Performance." Journal of Construction Engineering and Management, 122(1), 61-70.

Kines, P., Andersen, L. P. S., Spangenberg, S., Mikkelsen, K. L., Dyreborg, J., and Zohar, D. (2010). "Improving construction site safety through leader-based verbal safety communication." Journal of Safety Research, 41(5), 399-406.

Lasswell, H. D. (1948). "The structure and function of communication in society." The communication of ideas, 37, 215-228.

Lazarsfeld et al. 1954 Liao, P., Jiang, L., Liu, B., Chen, C., Fang, D., Rao, P., and Zhang, M. (2014). "A Cognitive Perspective on the Safety Communication Factors That Affect Worker Behavior." Journal of Building Construction and Planning Research, 2(3), 183197.

McPherson, M., Smith-Lovin, L., and Cook, J. M. (2001). "Birds of a Feather: Homophily in Social Networks." Annual Review of Sociology, 27, 415-444.

Menon, G., Raghubir, P., and Schwarz, N. (1995). "Behavioral Frequency Judgments: An Accessibility-Diagnosticity Framework." Journal of Consumer Research, 22(2), 212228.

Mohamed, S. (2002). "Safety Climate in Construction Site Environments." Journal of Construction Engineering and Management, 128(5), 375-384.

Pryke, S. (2012). Social Network Analysis in Construction. John Wiley \& Sons, Somerset, NJ, USA.

Rogers, E. M. (2003). Diffusion of Innovations, 5th Edition. Free Press, New York. Sawacha, E., Naoum, S., and Fong, D. (1999). "Factors affecting safety performance on construction sites." International Journal of Project Management, 17(5), 309315 .

US Department of Labor. (2010). "Women's Bureau (WB) - Nontraditional Occupations of Employed Women in 2010." <http://www.dol.gov/wb/stats/NontraJobs_2010.htm> (Oct. 7, 2011). 
Vecchio-Sadus, A. M. (2007). "Enhancing safety culture through effective communication." Safety Science Monitor, 11(3), 1-10.

Wagner, H., Kim, A., and Gordon, L. (2013). "Relationship between Personal Protective Equipment, Self-Efficacy, and Job Satisfaction of Women in the Building Trades." Journal of Construction Engineering and Management, 139(10), 4013005.

Zohar, D. (1980). "Safety climate in industrial organizations: Theoretical and applied implications." Journal of Applied Psychology, 65(1), 96-102.

Zuluaga, C. M., Namian, M., and Albert, A. (2016). "Impact of Training Methods on Hazard Recognition and Risk Perception in Construction." Construction Research Congress 2016, American Society of Civil Engineers, 2861-2871. 